University of Nebraska - Lincoln

DigitalCommons@University of Nebraska - Lincoln

\title{
Retrieval of subpixel snow-covered area and grain size from imaging spectrometer data
}

\author{
Thomas H. Painter \\ University of California - Santa Barbara \\ Jeff Dozier \\ University of California - Santa Barbara \\ Dar A. Roberts \\ University of California - Santa Barbara, dar@geog.ucsb.edu \\ Robert E. Davis \\ U.S. Army \\ Robert O. Green \\ California Institute of Technology
}

Follow this and additional works at: https://digitalcommons.unl.edu/usarmyresearch

Part of the Operations Research, Systems Engineering and Industrial Engineering Commons

Painter, Thomas H.; Dozier, Jeff; Roberts, Dar A.; Davis, Robert E.; and Green, Robert O., "Retrieval of subpixel snow-covered area and grain size from imaging spectrometer data" (2003). US Army Research. 82.

https://digitalcommons.unl.edu/usarmyresearch/82

This Article is brought to you for free and open access by the U.S. Department of Defense at DigitalCommons@University of Nebraska - Lincoln. It has been accepted for inclusion in US Army Research by an authorized administrator of DigitalCommons@University of Nebraska - Lincoln. 


\title{
Retrieval of subpixel snow-covered area and grain size from imaging spectrometer data
}

\author{
Thomas H. Painter ${ }^{\mathrm{a}, 1}$, Jeff Dozier ${ }^{\mathrm{b}, *}$, Dar A. Roberts ${ }^{\mathrm{c}, 2}$, Robert E. Davis ${ }^{\mathrm{d}, 3}$, Robert O. Green ${ }^{\mathrm{e}, 4}$ \\ ${ }^{a}$ Department of Geography and Institute for Computational Earth System Science, University of California, Santa Barbara, Santa Barbara, CA 93106, USA \\ ${ }^{\mathrm{b}}$ Donald Bren School of Environmental Science and Management, University of California, Santa Barbara, Santa Barbara, CA 93106, USA \\ ${ }^{\mathrm{c}}$ Department of Geography, University of California, Santa Barbara, Santa Barbara, CA 93106, USA \\ ${ }^{\mathrm{d}}$ U.S. Army, Cold Regions Research and Engineering Laboratory, Hanover, NH 03755, USA \\ ${ }^{\mathrm{e}}$ Jet Propulsion Laboratory, California Institute of Technology, Pasadena, CA 91109, USA
}

Received 21 June 2002; received in revised form 29 October 2002; accepted 2 November 2002

\begin{abstract}
We describe and validate an automated model that retrieves subpixel snow-covered area and effective grain size from Airborne Visible/ Infrared Imaging Spectrometer (AVIRIS) data. The model analyzes multiple endmember spectral mixtures with a spectral library of snow, vegetation, rock, and soil. We derive snow spectral endmembers of varying grain size from a radiative transfer model; spectra for vegetation, rock, and soil were collected in the field and laboratory. For three AVIRIS images of Mammoth Mountain, California that span common snow conditions for winter through spring, we validate the estimates of snow-covered area with fine-resolution aerial photographs and validate the estimates of grain size with stereological analysis of snow samples collected within $2 \mathrm{~h}$ of the AVIRIS overpasses. The RMS error for snowcovered area retrieved from AVIRIS for the combined set of three images was $4 \%$. The RMS error for snow grain size retrieved from a $3 \times 3$ window of AVIRIS data for the combined set of three images is $48 \mu \mathrm{m}$, and the RMS error for reflectance integrated over the solar spectrum and over all hemispherical reflectance angles is 0.018 .
\end{abstract}

(C) 2003 Elsevier Science Inc. All rights reserved.

Keywords: Snow; Albedo; Mapping; Imaging spectrometry; AVIRIS

\section{Introduction}

Mid-latitude alpine snow cover and its subsequent melt can dominate local-to-regional climate and hydrology in the world's mountainous regions. In recent research, snow hydrologists have investigated snowpack dynamics and snowmelt through spatially explicit models (Cline, Bales, \& Dozier, 1998; Colee, Painter, Rosenthal, \& Dozier, 2000;

* Corresponding author. Tel.: +1-805-893-5889; fax: +1-805-8937612.

E-mail addresses: tpainter@cires.colorado.edu (T.H. Painter), dozier@bren.ucsb.edu (J. Dozier), dar@geog.ucsb.edu (D.A. Roberts), Robert.E.Davis@erdc.usace.army.mil (R.E. Davis), rog@spectra.jpl.nasa.gov (R.O. Green).

${ }^{1}$ Current address: Cooperative Institute for Research in Environmental Sciences, University of Colorado, Boulder, CO 80309-0216 USA. Tel.: +1303-735-5744; fax: +1-425-740-9260.

${ }^{2}$ Tel.: +1-805-893-2276; fax: +1-805-893-3146

${ }^{3}$ Tel.: +1-603-646-4219; fax: +1-603-646-4397

${ }^{4}$ Tel.: +1-818-354-9136; fax: +1-818-393-4773.
Kirnbauer, Blöschl, \& Gutknecht, 1994; Luce, Tarboton \& Cooley, 1998, 1999) that require field measurements and remotely sensed imagery for initialization, re-initialization, and validation. Measurements of snow properties in the field provide direct determination, but at limited spatial and temporal extent and resolution and frequently under risky conditions. Subject to availability of instrument duty cycles and constrained by cloud cover, remote sensing techniques can regularly and safely provide maps of snow properties for the entire model domain at a range of resolutions.

Distributed snow models require the following spatially distributed parameters: snow-covered area, grain size, albedo, snow water equivalent, snow temperature profile, and meteorological conditions, including radiation. In this paper, we address the parameters that optical remote sensing can deliver: snow-covered area, grain size, and albedo. Active microwave remote sensing is close to delivering snow water equivalence (Shi \& Dozier, 2000a,b). The remaining parameters come from a combination of in situ measurements and topographic modeling. 
Snow-covered area in alpine terrain often varies at a spatial scale finer than that of the ground instantaneous field-of-view of the remote sensing instrument. This spatial heterogeneity poses a "mixed pixel" problem in that the sensor may measure radiance reflected from snow, rock, soil, and vegetation. To use the snow characteristics in distributed physical models, we must therefore map snowcovered area at subpixel resolution in order to accurately represent its spatial distribution. A measurement of effective grain size is needed to estimate the surface permeability and to infer spectral albedo. Normally, examiners of snow grains in the field characterize the grains by choosing the largest dimension. However, the effective grain size for radiative transfer applications is smaller. The radius of the sphere with the same surface-to-volume ratio of the actual grains represents many of the snow's characteristics adequately (Warren, 1982), or one can use a spatial autocorrelation function to represent an effective size even for grains that are heterogeneous and nonspherical (Mätzler, 1997). We must estimate the effective grain size for the fractional snow cover, accounting for the signal from the other surfaces within the pixel. Imaging spectrometers provide the spectral leverage necessary to infer these properties.

We describe and validate an automated model for the retrieval of subpixel snow-covered area and snow grain size from imaging spectrometer data. The algorithm uses multiple endmember spectral mixture analysis (Roberts et al., 1998) to simultaneously solve for subpixel snow cover and its grain size. An endmember is a pure surface cover with a distinctive spectral signature. Grain-size estimates coupled with an estimate of impurity concentration can then be used to estimate the albedo of the fractional snow cover (Warren \& Wiscombe, 1980).

We applied the algorithm to a set of Airborne Visible/ Infrared Imaging Spectrometer (AVIRIS) scenes of Mammoth Mountain, California acquired on April 5, 1994, March 29, 1996, and April 29, 1998. These scenes portray a wide range of snow cover and grain sizes. We validated the measurements of snow area with fine-resolution aerial photographs and the grain-size estimates with stereological analysis of snow samples.

\section{Remote sensing of snow-covered area and snow grain size}

The advent of imaging spectrometers, such as AVIRIS, both improves retrievals of snow cover and grain size mapped previously with multispectral instruments and allows the retrieval of previously inaccessible properties, such as atmospheric water vapor (Green et al., 1998) and snow algal content (Painter et al., 2001). AVIRIS measures reflected radiance in the wavelength range $0.4-2.5 \mu \mathrm{m}$ with $0.01-\mu \mathrm{m}$ spectral resolution, a nominal spatial resolution of $20 \mathrm{~m}$, and a $15^{\circ}$ scan angle either side of nadir. In the coming decades, a suite of airborne and spaceborne imaging spectrometers will provide extensive coverage of seasonally snow-covered regions, with data availability constrained by cloud cover and instrument duty cycles.

Vegetation above the snow surface occludes viewing the complete snow cover, so below timberline, the measures of subpixel snow-covered area represent the viewable snow cover through the vegetation canopy gaps.

\subsection{Snow-covered area}

The earliest remote sensing of snow properties focused primarily on mapping the snow extent with multispectral sensors (Rango \& Itten, 1976), such as the Landsat Multispectral Scanning Subsystem (MSS) and Thematic Mapper (TM) and the NOAA Advanced Very High Resolution Radiometer (AVHRR). Dozier (1989) proposed a suite of normalized band differences for mapping snow and qualitative grain size with TM data, and most current multispectral schemes for "binary" mapping of snow cover, by which each pixel is classified as either "snow" or "not snow," are derived from his method (Hall, Riggs, \& Salomonson, 1995). Rosenthal and Dozier (1996) extended this work by developing linear spectral mixture analysis for subpixel snow-covered area from Landsat TM.

Imaging spectroscopy enables mapping land cover at the subpixel scale via spectral mixture analysis, a method of inverting multispectral and hyperspectral data for the subpixel coverage of snow, vegetation, rock, and other surfaces (Adams, Smith, \& Gillespie, 1993; Mertes, Smith, \& Adams, 1993; Okin, Roberts, Murray, \& Okin, 2001; Roberts et al., 1998). Nolin, Dozier, and Mertes (1993) first demonstrated spectral mixture analysis for subpixel snow cover mapping. They modeled two AVIRIS datasets with single endmember suites of (a) snow, rock/soil, water, and vegetation, and (b) snow, shade, and vegetation. The spectral band subset consisted of 18 bands: 3 in visible wavelengths $(0.46,0.55,0.66 \mu \mathrm{m}), 3$ in the near-infrared $(0.72$, $0.85,0.94 \mu \mathrm{m})$, and 12 bands spanning the $1.03-\mu \mathrm{m}$ ice absorption feature.

Painter, Roberts, Green, and Dozier (1998) demonstrated that subpixel snow mapping would improve if the snow endmember were allowed to vary to match the spectral shape of the pixel's snow reflectance. For five snow endmembers with grain sizes ranging from 120 to 500 $\mu \mathrm{m}$, selected from AVIRIS imagery, they analyzed the whole AVIRIS band set (omitting those bands where water vapor absorption makes the atmosphere nearly opaque) with snow endmembers of each grain size coupled with a rock and a vegetation endmember. Selection of the spectral mixture model at each pixel with the smallest error produced an optimized map of snow-covered area and a best choice among a range of grain sizes. Because the spectral reflectance of snow decreases with increasing grain size, varying grain sizes in a scene translate into variability of spectral reflectance, and multiple snow endmembers of different grain sizes are necessary to characterize the snow. 


\subsection{Snow grain size}

Grain size is the snow parameter that determines its spectral albedo in the near-infrared wavelengths, while absorbing impurities and, for shallow snow only, snow water equivalence affect its albedo in the visible spectrum (Wiscombe \& Warren, 1980). For calculation of albedo (angularly integrated reflectance), an "equivalent sphere" with the same volume-to-surface ratio as the actual snow grains works well, although such a simplification is possibly inadequate for calculation of the angular details of the reflectance (Leroux, Deuze, Goloub, Sergent, \& Fily et al., 1998; Warren, 1982). Dozier, Schneider, and McGinnis (1981) showed that AVHRR data could qualitatively retrieve both snow grain size and snow water equivalence. Dozier and Marks (1987) explored the possibility of mapping the spatial distribution of snow grain size with TM data, again arriving at qualitative estimates. Bourdelles and Fily (1993) mapped grain size over Adélie, Antarctica using TM data and a two-stream snow reflectance model. Their results matched those found in the literature but they lacked field validation. Fily, Bourdelles, Dedieu, and Sergent (1997) estimated grain size from TM data over the Haute Savoie region of the French Alps using a model for the bidirectional reflectance of snow.

Estimates of grain size from Landsat TM rely on bands 4 and 5, which span the wavelength ranges $0.76-0.90$ and $1.55-1.75 \mu \mathrm{m}$. Band 4 is only modestly sensitive to grain size, and snow reflectance in band 5 declines to nearly $0 \%$ reflectance once the snow grain radius reaches $250 \mu \mathrm{m}$. Therefore, robust measures of grain size are more tractable with an instrument that covers at high spectral resolution the wavelength range $1.0-1.3 \mu \mathrm{m}$, where the spectral reflectance of snow is most sensitive to grain size.

Nolin and Dozier (1993) described a method for remotely sensing grain size using the snow reflectance at $1.03 \mu \mathrm{m}$, the wavelength of a prominent ice absorption feature. Their method was sensitive to sensor noise and required solid knowledge of the solar and viewing geometry. Subsequently, they presented a more robust algorithm (Nolin \& Dozier, 2000) that integrates across the entire $1.03-\mu \mathrm{m}$ absorption feature, which is scaled spectrally by its continuum.

Green, Dozier, Roberts, and Painter (2002) used AVIRIS data to map the solid, liquid, and vapor phases of water by analyzing and distinguishing among the absorption caused by the different phases of water at $0.94 \mu \mathrm{m}$ (vapor), $0.98 \mu \mathrm{m}$ (liquid), and $1.03 \mu \mathrm{m}$ (solid). They quantified the distribution of optical path lengths for ice (related to grain size) and liquid water (related to surface liquid-water content).

All previous grain-size algorithms have the constraint that each pixel analyzed must have complete snow cover. Here we accommodate the mixed-pixel problem by determining the grain size of the fractional snow cover.

\section{Model description}

Derived from MESMA (Roberts et al., 1998), our model MEMSCAG (multiple endmember snow-covered area and grain size) maps snow and its grain size simultaneously using spectral mixture analysis coupled with a radiative transfer model. We allow the number of endmembers and the endmembers themselves to vary pixel-by-pixel and thereby address subscene spatial heterogeneity.

\subsection{Snow library endmembers}

An endmember is a pure surface cover with a distinctive spectral signature. MEMSCAG uses a snow spectral library generated with model calculations of snow reflectance spectra for monodispersions of spheres of radii 10 $1100 \mu \mathrm{m}$. We calculated their single-scattering properties at each AVIRIS band with Mie theory (Mie, 1908; Nussenzveig \& Wiscombe, 1980; Wiscombe, 1980) and the angular distribution of spectral reflected intensity with a discrete-ordinates radiative transfer model (DISORT, Stamnes, Tsay, Wiscombe, \& Jayaweera, 1988). For each AVIRIS scene, we estimated the proportions of direct and diffuse spectral irradiance with SBDART, the Santa Barbara DISORT Atmospheric Radiative Transfer model (Ricchiazzi, Yanf, Gautier, \& Sowle, 1998), and we generated a snow spectral library of hemispherical-directional reflectance factors $(R)$ for each AVIRIS acquisition, varying according to the solar geometry and diffuse and direct components of irradiance.

$$
\begin{aligned}
& R_{\lambda}\left(\theta_{0}, \phi_{0} ; \theta_{\mathrm{r}}, \phi_{\mathrm{r}}\right) \\
& =\pi f_{\mathrm{r} \lambda}\left(\theta_{0}, \phi_{0} ; \theta_{\mathrm{r}}, \phi_{\mathrm{r}} ; \frac{E_{\lambda, \text { diffuse }}}{\mu_{0} E_{\lambda, \text { direct }}+E_{\lambda, \text { diffuse }}}\right) \\
& =\frac{\pi L_{\lambda}\left(\theta_{\mathrm{r}}, \phi_{\mathrm{r}}\right)}{\mu_{0} E_{\lambda, \text { direct }}\left(\theta_{0}, \phi_{0}\right)+E_{\lambda, \text { diffuse }}}
\end{aligned}
$$

$f_{\mathrm{r}, \lambda}$ is the hemispherical-directional reflectance distribution function (HDRDF), $\theta$ and $\phi$ are zenith and azimuth angles, and the subscripts 0 and $\mathrm{r}$ signify incident and reflected. $L_{\lambda}$ is reflected radiance, $E_{\lambda \text {,direct }}$ is the direct incident irradiance on a surface normal to the beam, $E_{\lambda \text {,diffuse }}$ is the diffuse incident irradiance, and. We also calculated the broad-band albedo associated with each grain size for the given solar geometry and diffuse and direct components of irradiance with DISORT, assuming that the snow cover is clean.

This configuration of the MEMSCAG model does not use a digital elevation model. Hence, we model only the zenith reflectance factor, corresponding to $\theta_{\mathrm{r}}=0$. Fig. 1 shows a subset of the snow spectral library. Field measurements have shown that the hemispherical-directional reflectance of snow varies little near-nadir (Painter, 2002; Warren, Brandt, \& Hinton, 1998). 


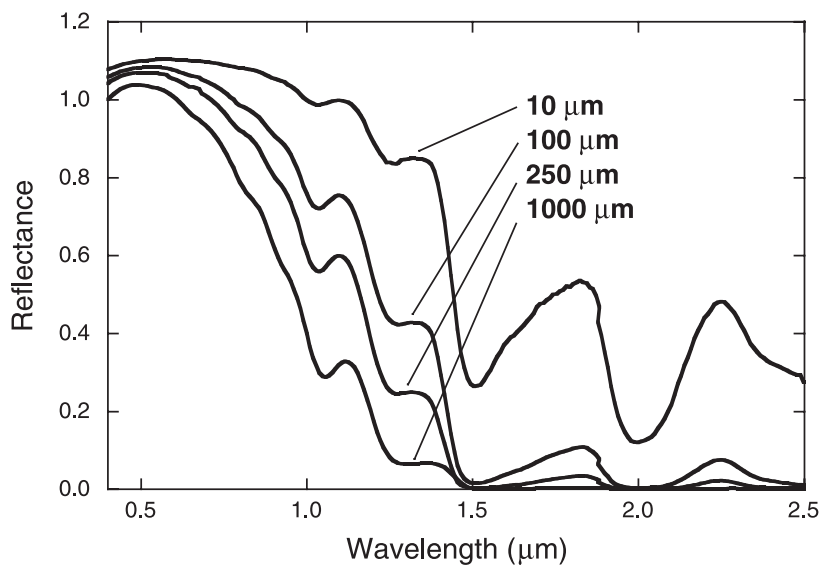

Fig. 1. Subset of snow spectral library for April 29, 1998 for grain size 10$1000 \mu \mathrm{m}$.

\subsection{Rock, soil, vegetation, and lake ice endmembers}

With an Analytical Spectral Devices FieldSpec FR field spectroradiometer, we measured 60 spectral endmembers for vegetation, rock, soil, and lake ice in the Sierra Nevada and calculated their hemispherical-directional reflectance factors using Eq. (1). Vegetation spectra were measured in situ with a nadir view from above the canopy from ladders and ski lifts. Rock, soil, and lake ice spectra were measured in situ with a nadir view. We convolved these spectra, which were sampled at a spectral resolution finer than AVIRIS, to the AVIRIS bandpasses using the band center and a Gaussian pass filter. Fig. 2 shows a subset of the non-snow spectral library.

We measured a wide range of spectra for vegetation and rock in order to span and populate the range of possible angular reflectances near-nadir. The model does not attempt to identify vegetation species or rock/soil mineralogy, so attention to specific bidirectional reflectance is not necessary.

\subsection{Retrieval of apparent surface reflectance}

MEMSCAG analyzes apparent surface reflectance spectra $\left(R_{\mathrm{S}, \lambda}\right)$, which is the ratio of the radiance $L$ measured at the sensor to the hypothetical radiance from a completely reflecting Lambertian target given the same irradiance on a level surface under the atmospheric conditions and solar geometry at the time of the acquisition. We inverted AVIRIS-calibrated radiance for apparent surface reflectance using a nonlinear least squares water vapor fitting model (Green, Conel, \& Roberts, 1993) that incorporates the atmospheric transmission model MODTRAN4 (Berk et al., 1998). This algorithm accounts for atmospheric spatial heterogeneity by solving for the atmospheric conditions pixel-by-pixel from the AVIRIS radiance data and computes $R_{S, \lambda}$ (Green, 2001).

$R_{\mathrm{S}, \lambda}=\left(\frac{\mu_{0} E_{0, \lambda} T_{\mathrm{d}, \lambda} T_{\mathrm{u}, \lambda}}{\pi L_{\mathrm{AVIRIS}, \lambda}-\mu_{0} E_{0, \lambda} R_{\mathrm{a}, \lambda}}+S_{\lambda}\right)^{-1}$
$E_{0}$ is the exoatmospheric solar irradiance, $T_{\mathrm{d}}$ is the downward direct and diffuse transmittance of the atmosphere, $T_{\mathrm{u}}$ is the upward atmospheric transmittance to AVIRIS, $L_{\text {AVIRIS }, \lambda}$ is the total upwelling spectral radiance at AVIRIS, $R_{\mathrm{a}}$ is the upward reflectance of the atmosphere, and $S$ is its downward reflectance.

\subsection{Spectral mixture analysis}

Linear spectral mixture analysis is based on the assumption that the radiance measured at the sensor is a linear combination of radiances reflected from individual surfaces (endmembers) whose spectral signatures are unique and well separated above a random image noise level (Sabol, Adams, $\&$ Smith, 1992). The linear assumption is appropriate for spatial scenarios such as snow and rock cover above timberline where the surface is near planar. Nonlinear analysis, which accounts for multiple scattering between surfaces, is necessary when the surface has a structure, such as vegetation that reflects and transmits radiation to the snow or soil substrate and other vegetation (Roberts, Smith, \& Adams, 1993).

Spectral mixture analysis is based on a set of simultaneous linear equations:

$R_{\mathrm{S}, \lambda}=\sum_{i=1}^{N} F_{i} R_{\lambda, i}+\varepsilon_{\lambda}$

$F_{i}$ is the fraction of endmember $i, R_{\lambda, i}$ is the hemisphericaldirectional reflectance factor of endmember $i$ at wavelength $\lambda, N$ is the number of spectral endmembers, and $\varepsilon_{\lambda}$ is the residual error at $\lambda$ for the fit of the $N$ endmembers (Gillespie et al., 1990). We solve the system of equations by modified Gram-Schmidt orthogonalization (Golub \& Van Loan, 1996).

The residual error is a rearrangement of the linear mixture model:

$\varepsilon_{\lambda}=R_{\mathrm{S}, \lambda}-\sum_{i=1}^{N} F_{i} R_{\lambda, i}$

Analysis of residuals reveals the spectral regions of poor modeling and can be useful for separating near-degenerate spectra (Roberts et al., 1993).

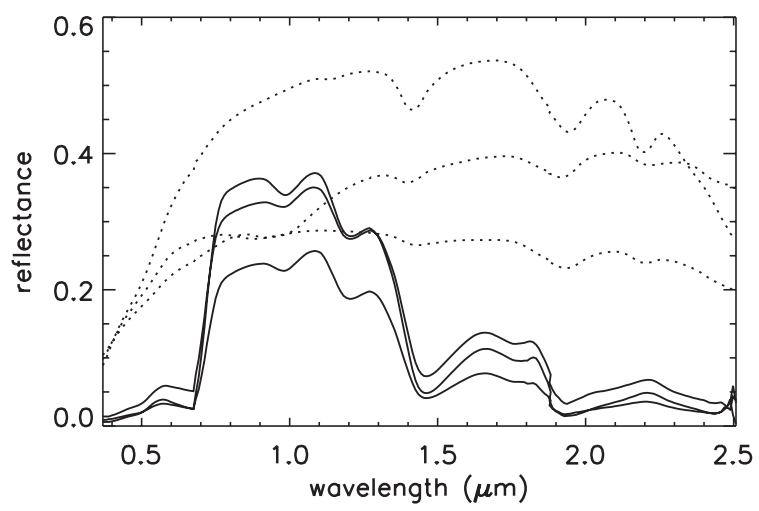

Fig. 2. Subset of non-snow spectral library, for rock/soil (dashed) and vegetation (solid). 
The root mean squared error provides a spectrum-wide measure of goodness-of-fit for a mixture model:

$\mathrm{RMSE}=\left(\frac{1}{M} \sum_{\lambda=1}^{M} \varepsilon_{\lambda}^{2}\right)^{1 / 2}$

$M$ is the number of imaging spectrometer bands used. Painter et al. (1998) and Roberts et al. (1998) used the RMSE as a fundamental metric for optimizing selection of model results in the multiple endmember spectral mixture analysis.

The estimate of subpixel snow-covered area comes from the shade-normalized snow fraction $f_{\mathrm{S}}$ :

$f_{\mathrm{S}}=\frac{F_{\mathrm{S}}}{\sum_{p \in \mathrm{S}, \mathrm{v}, \mathrm{r}} F_{\mathrm{p}}}=\frac{F_{\mathrm{S}}}{1-F_{\text {shade }}}$

$F_{\mathrm{s}}$ is the snow spectral fraction, $F_{\mathrm{p}}$ are the physical spectral fractions (non-shade), and $F_{\text {shade }}$ is the spectral fraction of photometric shade. $F_{\text {shade }}$ is the additive complement to the sum of the physical spectral fractions (i.e., $\sum_{p \in \mathrm{S}, \mathrm{V}, \mathrm{R}} F_{\mathrm{p}}+$ $F_{\text {shade }}=1$ ). Normalizing by the additive complement of the shade fraction accounts for topographic effects on irradiance (Adams et al., 1993).

\subsection{MEMSCAG model}

MEMSCAG analyzes individual linear spectral mixtures for each permutation of two or more endmembers of the spectral library, in which no more than one endmember from a surface cover class is present (i.e., at most one snow endmember). We include the constraint that the spectral fractions sum to 1.0. A model is considered valid if: (a) spectral fractions are in the range $[-0.01,1.01]$, (b) overall RMSE $<2.5 \%$, and (c) no seven consecutive residuals exceed $2.5 \%$. For each $n$-endmember suite of models that meet the constraints for a pixel, MEMSCAG selects the snow area and grain-size values associated with the smallest error. MEMSCAG then attributes to the pixel the snowcovered area and snow grain size of the valid model that has the fewest endmembers.

MEMSCAG incorporates the following assumptions: (a) the variability in the hemispherical-directional reflectance factor for the solar geometry and atmospheric conditions at the time of each AVIRIS acquisition is negligible, i.e., $R_{\lambda}\left(\theta_{0}, \phi_{0}, 0,0\right) \approx R_{\lambda}\left(\theta_{0}, \phi_{0}, \theta_{\mathrm{r}}, \phi_{\mathrm{r}}\right)$ within the range of angles $\left[\theta_{\mathrm{r}}, \phi_{\mathrm{r}}\right]$ observed from AVIRIS; (b) the effects of impurities (dust, soot, and vegetation litter) and the effects of thin snow on snow spectral reflectance are not separable and these effects do not impact retrievals of snow area and grain size; (c) linear spectral mixture analysis is valid for hyperspectral scenes of alpine terrain; (d) liquid water in the snow does not affect the retrievals of snow-covered area and grain size; (e) effects of surface roughness on the bidirectional reflectance of snow for AVIRIS view geo- metries over rough terrain are negligible; and (f) the vegetation canopy is snow-free.

Painter (2002) investigates the first assumption (a) and shows that retrievals of snow area and grain size are not sensitive to angular variability caused by the AVIRIS scanning range and the topography. Assumption (b) can perhaps be addressed with new digital elevation data from the Shuttle Radar Topography Mission (van Zyl, 2001) when those data are available in corrected form; robust incorporation of impure/thin snow endmembers will facilitate the discrimination of dirty/shallow snow from shaded slopes that have similar spectral signatures. Assumption (c) has been validated in areas where trees are absent or sparse (Nolin et al., 1993; Painter et al., 1998; Rosenthal \& Dozier, 1996). However, we know that vegetated regions exhibit nonlinear mixing (Ray \& Murray, 1996; Roberts et al., 1993) so nonlinear mixture analysis may become necessary as canopy density increases. Green et al. (2002) examine the sensitivities associated with assumption (d); because MEMSCAG incorporates most AVIRIS bands in the visible and near-infrared spectrum, retrievals should be insensitive to the subtle shifts in the shape of the reflectance spectrum that result from liquid water in the snow. While surface roughness (i.e., sastrugi, suncups) can
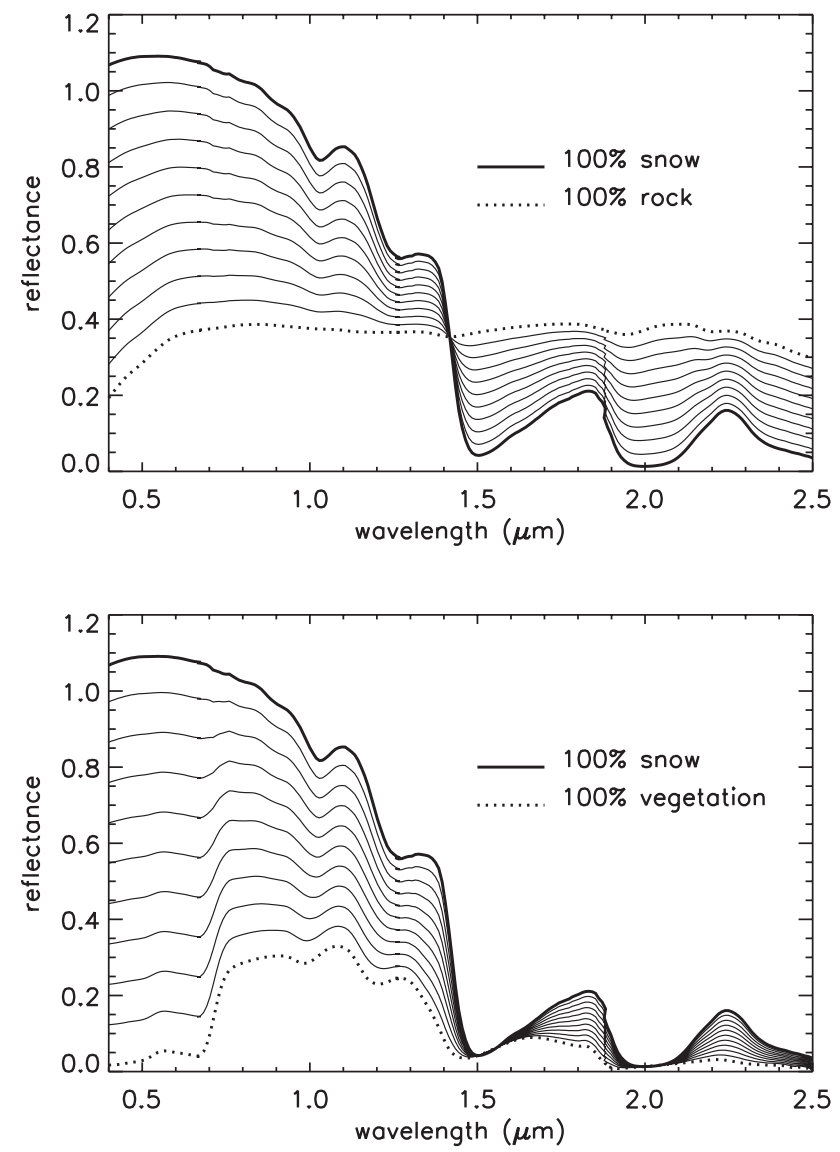

Fig. 3. Example of spectral mixtures used in sensitivity study, for the $50-\mu \mathrm{m}$ snow endmember, rock endmember (top), and vegetation endmember (bottom) 
affect the bidirectional reflectance distribution function of snow, Warren et al. (1998) found the effect of sastrugi negligible for near-nadir views. Moreover, they found that sastrugi have little effect on the BRDF for view angles less than $30^{\circ}$ in the principal plane and for view zenith angles less than $50^{\circ}$ for $\lambda=0.9 \mu \mathrm{m}$ and solar zenith angle $\theta_{0}=67^{\circ}$. For smaller zenith angles, the effect would be even smaller. Therefore, assumption (e) should be valid for the AVIRIS scenes examined, and we analyze the distribution of solar and view geometries below. Assumption (f) will often be invalid because coniferous canopies can hold sufficient depths of snow to create an optically thick layer of snow and render the spectral reflectance closer to that of snow than vegetation. This change in spectral reflectance will result in inflated measures of subpixel snow area and a lower estimate of grain size (Section 4). Because of the inherent reflectance and textural variability with varying interception of snow by the canopy, we recommend a temporal analysis of the continuity of the mapped canopy closure with multiple scenes rather than an explicit radiative treatment in MEMSCAG.

\section{Sensitivity study}

We performed a modeling study to determine the inherent sensitivity of retrievals of snow area and grain size to the fractional snow cover, to the complementary surface cover type (vegetation or rock), and to the snow grain size. We generated six synthetic hyperspectral scenes, consisting of spectral mixtures of snow and rock, and of snow and vegetation, for snow grain sizes 50, 250, and $1000 \mu \mathrm{m}$, for snow fractions ranging from $0 \%$ to $100 \%$ and the rock or vegetation fraction as the additive complement to sum to
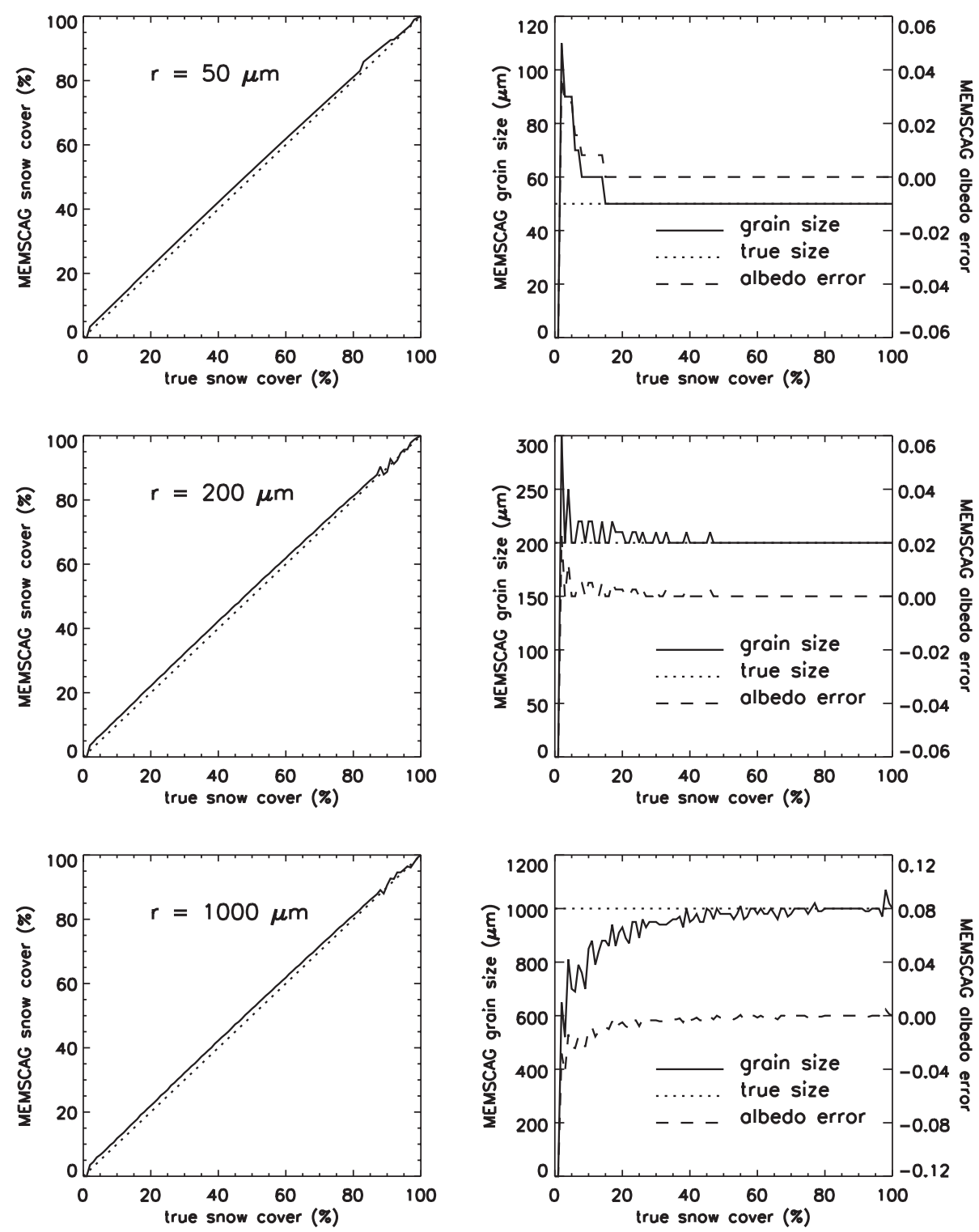

Fig. 4. Sensitivity modeling results for 50-, 200-, and 1000- $\mu \mathrm{m}$ snow endmembers and a granite endmember. 
$100 \%$. We used a granite spectrum for the rock endmember and a lodgepole pine spectrum for the vegetation endmember. Each "scene" was a single row of 101 samples and 224 bands. Fig. 3 shows a subset of the spectra in the $50-\mu \mathrm{m}$ rock and vegetation synthetic scenes, incremented by $10 \%$ mixtures.

Fig. 4 demonstrates that MEMSCAG is robust in mapping subpixel snow area when the non-snow endmember is rock, for all snow cover fractions and grain size, with only a $2 \%$ maximum positive error. MEMSCAG grain-size retrievals are likewise robust for most snow cover fractions. However, the sensitivity of the grain-size retrievals to snow cover depends on grain size. Grain-size retrievals were accurate down to snow fractions of $15 \%$ for the $50-\mu \mathrm{m}$ grain size, $45 \%$ for the $200-\mu \mathrm{m}$ grain size, and $55 \%$ for the $1000-\mu \mathrm{m}$ grain size. For a snow cover fraction of $10 \%$, retrieval errors were $10 \mu \mathrm{m}$ for the $50-\mu \mathrm{m}$ grain size, $20 \mu \mathrm{m}$ for the $200-\mu \mathrm{m}$ grain size, and $-200 \mu \mathrm{m}$ for the $1000-\mu \mathrm{m}$ grain-size image. Albedo retrievals were within 0.02 for snow fractions to $5 \%$ for the $50-\mu \mathrm{m}$ grain size, $<5 \%$ for the $200-\mu \mathrm{m}$ grain size, and $10 \%$ for the $1000-\mu \mathrm{m}$ grain size.

Fig. 5 shows that as the vegetation fraction increases past $20 \%$ (as the snow fraction decreases below $80 \%$ ), MEMSCAG underestimates the grain size increasingly, especially for larger grain sizes. MEMSCAG also has a maximum snow-area error of $\sim 10 \%$ near a snow fraction of $50 \%$. The discrepancies between MEMSCAG results for rock and vegetation mixtures most likely derive from the liquid water absorption in the vegetation spectrum at $\lambda \approx 0.98 \mu \mathrm{m}$ and absent from the rock spectrum. As the vegetation fraction increases, the liquid water absorption increasingly draws the $1.03-\mu \mathrm{m}$ ice absorption feature toward shorter wavelengths,
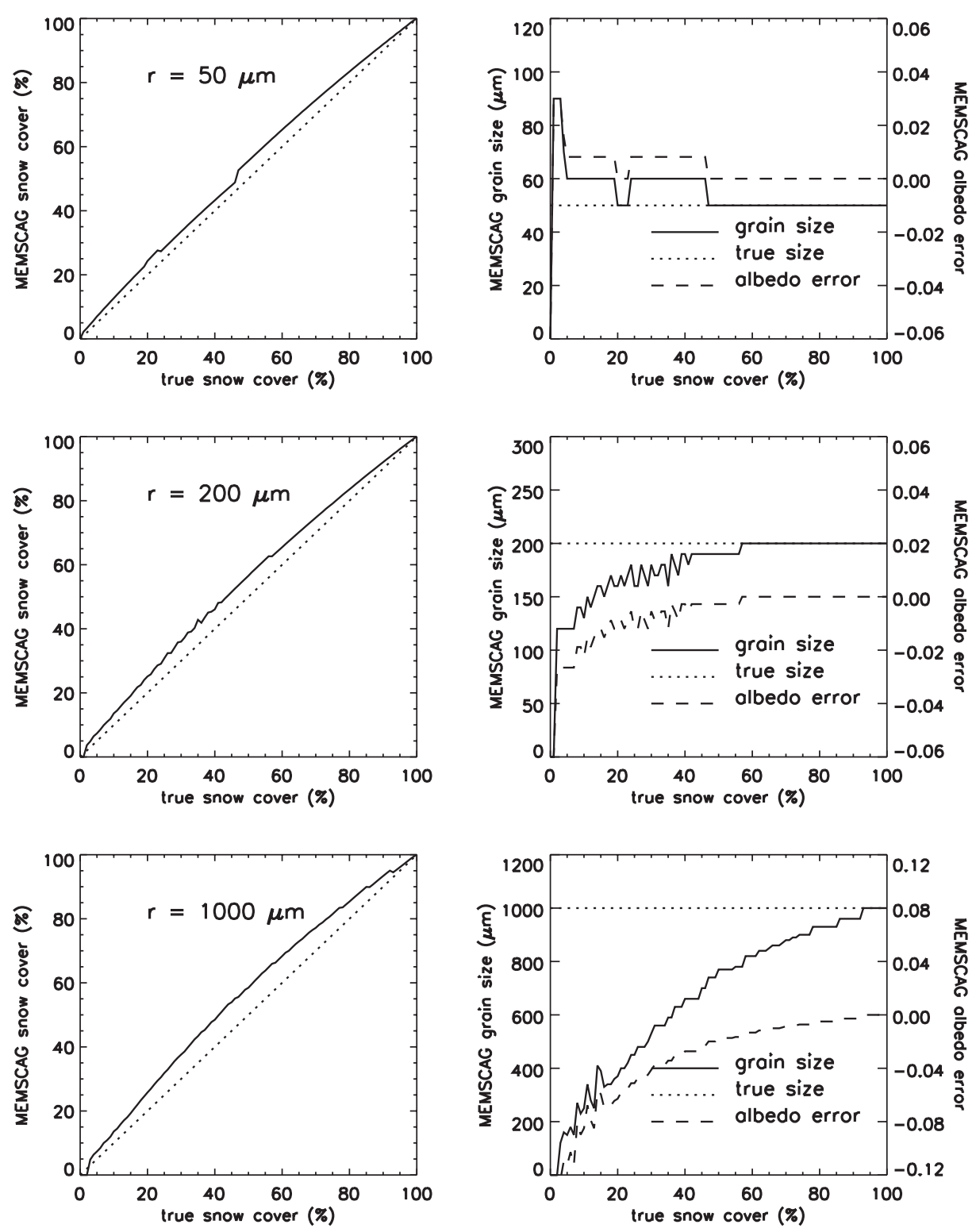

Fig. 5. Sensitivity modeling results for 50-, 200-, and 1000- $\mu \mathrm{m}$ snow endmembers and a vegetation endmember. 
making discrimination of the spectral mixture of snow and its associated grain size more difficult. The positive bias in MEMSCAG snow-area results could be caused by the commonality of spectral signatures between snow and vegetation for $\lambda>0.8 \mu \mathrm{m}$. These specific mixtures of snow with vegetation therefore must be mathematically degenerate with other mixtures with higher snow fractions. Grainsize retrievals were accurate (grain size error $=0.0$ ) down to snow fractions of $50 \%$ for the $50-\mu \mathrm{m}$ grain size, $55 \%$ for the $200-\mu \mathrm{m}$ grain size, and $90 \%$ for the $1000-\mu \mathrm{m}$ grain size. Albedo retrievals were within 0.02 for snow fractions down to $5 \%$ for the $50-\mu \mathrm{m}$ grain size, $10 \%$ for the $200-\mu \mathrm{m}$ grain size, and $45 \%$ for the $1000-\mu \mathrm{m}$ grain size. For a snow cover fraction of $10 \%$, grain-size retrieval errors were $10 \mu \mathrm{m}$ for the $50-\mu \mathrm{m}$ grain size, $-60 \mu \mathrm{m}$ for the $200-\mu \mathrm{m}$ grain size, and $-700 \mu \mathrm{m}$ for the $1000-\mu \mathrm{m}$ grain-size image. The large underestimates in grain size for the $1000-\mu \mathrm{m}$ grain size would cause significant underestimates of infiltration rates in the surface snow layer.

\section{Sources of data for validation}

We used three AVIRIS images of Mammoth Mountain, California (Fig. 6) for validation of the estimates of snowcovered area and grain size; these were acquired on April 5, 1994, March 29, 1996, and April 29, 1998. Snow conditions on these dates ranged from fresh, fine-grained to coarse, melting snow. The imaged region of Fig. 6 is about $11 \times 9$ $\mathrm{km}$ with a $17-\mathrm{m}$ ground instantaneous field of view. Table 1 shows the solar ephemeris data, atmospheric conditions, and snow conditions for each AVIRIS scene. The snow depths and snow water equivalents at the Mammoth Mountain Cooperative Snow Study Site (http://neige.bren.ucsb.edu/ mmsa) at $2960 \mathrm{~m}$ were large enough to make the snowpack optically semi-infinite on all image dates.

\subsection{Snow-covered area}

High-resolution color-infrared photographs accompany each AVIRIS acquisition. Their spatial resolution is approximately $1 \mathrm{~m}$, compared with a spatial resolution of $\sim 17 \mathrm{~m}$ for AVIRIS flying above a surface whose elevation is 3000 $\mathrm{m}$. We digitized the photographs at $600 \mathrm{dpi}$ in color and coregistered each to its respective AVIRIS scene (Fig. 7). From each scene, we randomly picked 20 subregions of size $22 \times 22$ pixels from the AVIRIS scene and the corresponding $210 \times 210$ pixels from the aerial photograph. Co-registration errors for photographs to the AVIRIS base scene were about 1 AVIRIS pixel, i.e., $17 \mathrm{~m}$.

\subsection{Snow grain size}

Snow samples were collected within $1 \mathrm{~h}$ of the time of acquisition for each image; three samples on April 5, 1994, seven samples on March 29, 1996, and nine samples on
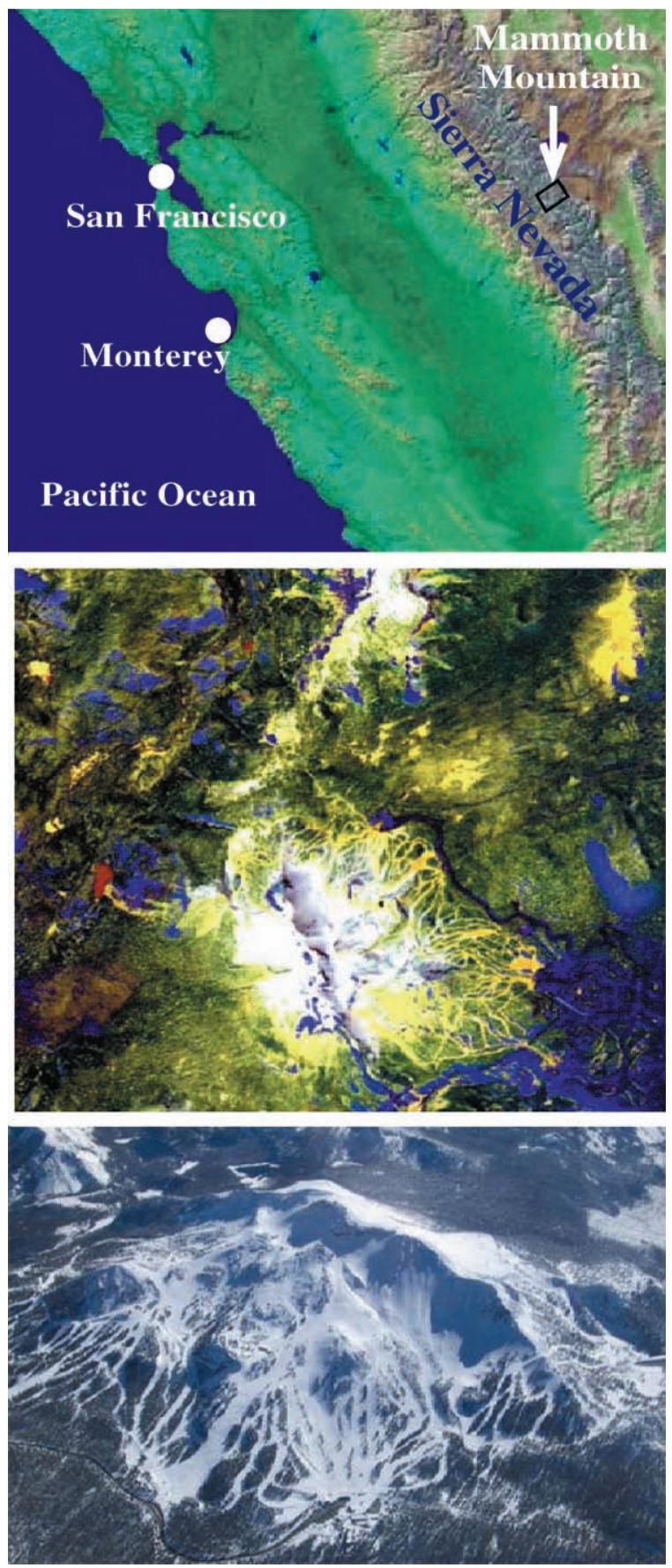

Fig. 6. AVIRIS data cube $(11 \times 9 \mathrm{~km}, \sim 17 \mathrm{~m}$ IFOV) of Mammoth Mountain, California acquired on April 5, 1994. The sides show the spectral reflectance for edge pixels of the scene, where red represents high reflectance and black/blue represent low reflectance. Mammoth Mountain is located at $37^{\circ} 37^{\prime} \mathrm{N}, 119^{\circ} 02^{\prime} \mathrm{W}$ and has a summit elevation of $3370 \mathrm{~m}$.

April 29, 1998. Snow samples came from all cardinal aspects and included level areas. In 1994 and 1996, we located the sampling locations on topographic maps. In 1998, we used differentially corrected Global Positioning System measurements. We estimate the location accuracy of the 1994 and 1996 samples to be $\sim 40 \mathrm{~m}$ and the location accuracy of the 1998 samples at $\sim 2 \mathrm{~m}$. The samples were 
Table 1

Solar ephemeris and atmospheric conditions for three AVIRIS acquisitions at Mammoth Mountain, California, with meteorological data from the Mammoth Mountain Cooperative Snow Study Site, located at $2960 \mathrm{~m}$ on its north slope

\begin{tabular}{|c|c|c|c|}
\hline & April 5, 1994 & March 29, 1996 & April 29, 1998 \\
\hline $\begin{array}{l}\theta_{0} \text {, solar zenith } \\
\text { angle }\left({ }^{\circ}\right)\end{array}$ & 31 & 37 & 23 \\
\hline $\begin{array}{l}\phi_{0}, \text { solar azimuth, } \\
\text { clockwise from } \\
\text { north }\left({ }^{\circ}\right)\end{array}$ & 179 & 209 & 166 \\
\hline $\begin{array}{l}\text { Air temperature } \\
\text { at } 2960-\mathrm{m} \\
\text { elevation }\left({ }^{\circ} \mathrm{C}\right)\end{array}$ & 4.0 & -7.3 & 7.6 \\
\hline $\begin{array}{l}\text { Precipitable water } \\
\text { vapor retrieved } \\
\text { from AVIRIS } \\
\text { data }(\mathrm{mm})\end{array}$ & 21 & 26 & 16 \\
\hline $\begin{array}{l}\text { Aerosol optical } \\
\text { depth }(\lambda=0.55 \mu \mathrm{m})\end{array}$ & 0.08 & 0.08 & 0.08 \\
\hline Snow condition & $\begin{array}{l}\text { Fresh, } \\
\text { fine-grained }\end{array}$ & $\begin{array}{l}\text { Fresh, } \\
\text { fine-grained }\end{array}$ & $\begin{array}{l}\text { Melting, } \\
\text { coarse-grained }\end{array}$ \\
\hline Snow depth (m) & 1.6 & 4.1 & 5.0 \\
\hline $\begin{array}{l}\text { Snow water } \\
\text { equivalence (m) }\end{array}$ & 0.6 & 1.6 & 2.4 \\
\hline
\end{tabular}

prepared for stereological analysis in a cold room immediately after collection in order to avoid further metamorphism. We analyzed each sample for snow grain radius using stereological techniques for plane sections (Davis, Dozier, \& Perla, 1987). The snow grain radius came from the sphere with the same surface area to volume ratio as inferred from the stereological analysis.
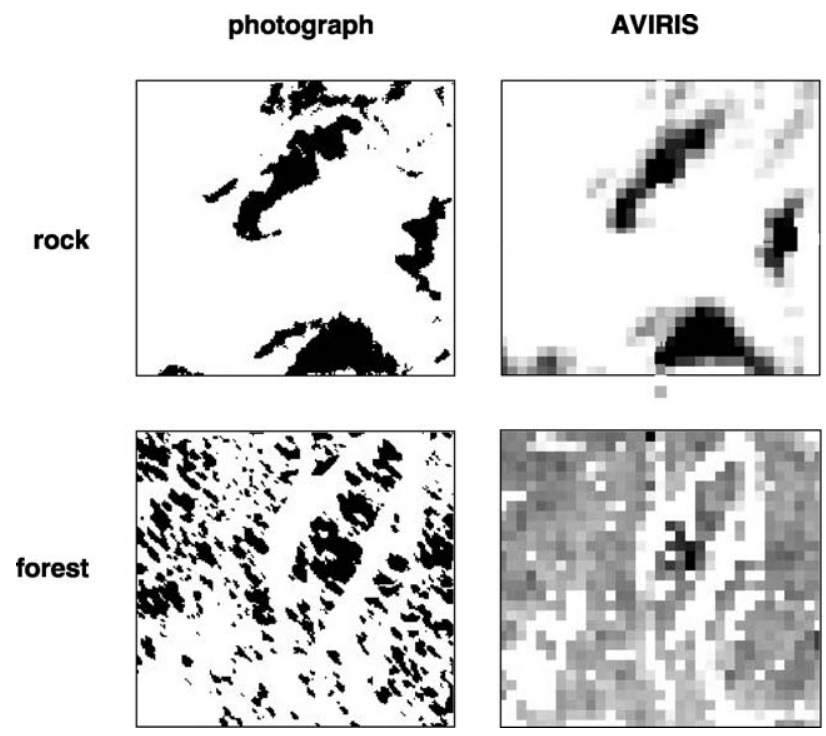

Fig. 7. Subregions of co-registered aerial photographs (left) and AVIRIS snow-covered area images (right).

\section{Results}

We present the results of MEMSCAG analysis of the three AVIRIS acquisitions for subpixel snow fraction and snow grain size on April 5, 1994 (Fig. 8), March 29, 1996 (Fig. 9), and April 29, 1998 (Fig. 10).

The April 5, 1994 scene shows high snow cover above timberline and patchy snow cover below timberline. Because vegetation canopies obscure the view of the complete ground cover from AVIRIS, spectral mixture analysis can only produce maps of viewable snow cover. Inference of the snow cover below the canopy will rely on empirical relationships developed from field and model data. Snow cover was nearly complete above timberline on March 29, 1996. Snow cover was likewise nearly complete above timberline on April 29, 1998, an El Niño year with heavy snowfall throughout the Sierra Nevada.

MEMSCAG maps grain sizes that are inversely related to elevation, particularly in the April 5, 1994 scene (Fig. 8). Grain sizes were uniformly small in the March 29, 1996 acquisition because of recent snowfall and consistently cold temperatures (Fig. 9). Grain sizes were large in the April 29, 1998 acquisition because of rapid metamorphism driven by a period of high temperatures and strong irradiance (Fig. 10). All scenes exhibit consistent spatial continuity in grain

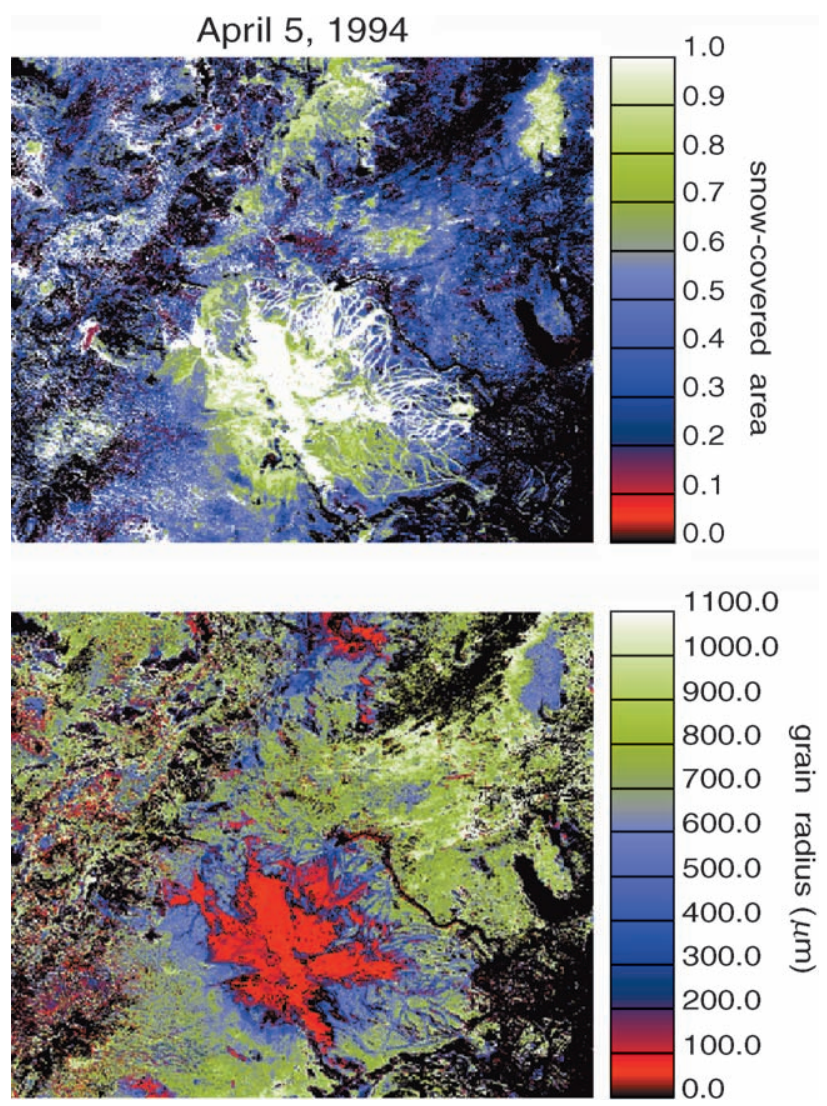

Fig. 8. MEMSCAG snow-covered area and grain size for the AVIRIS acquisition on April 5, 1994. 

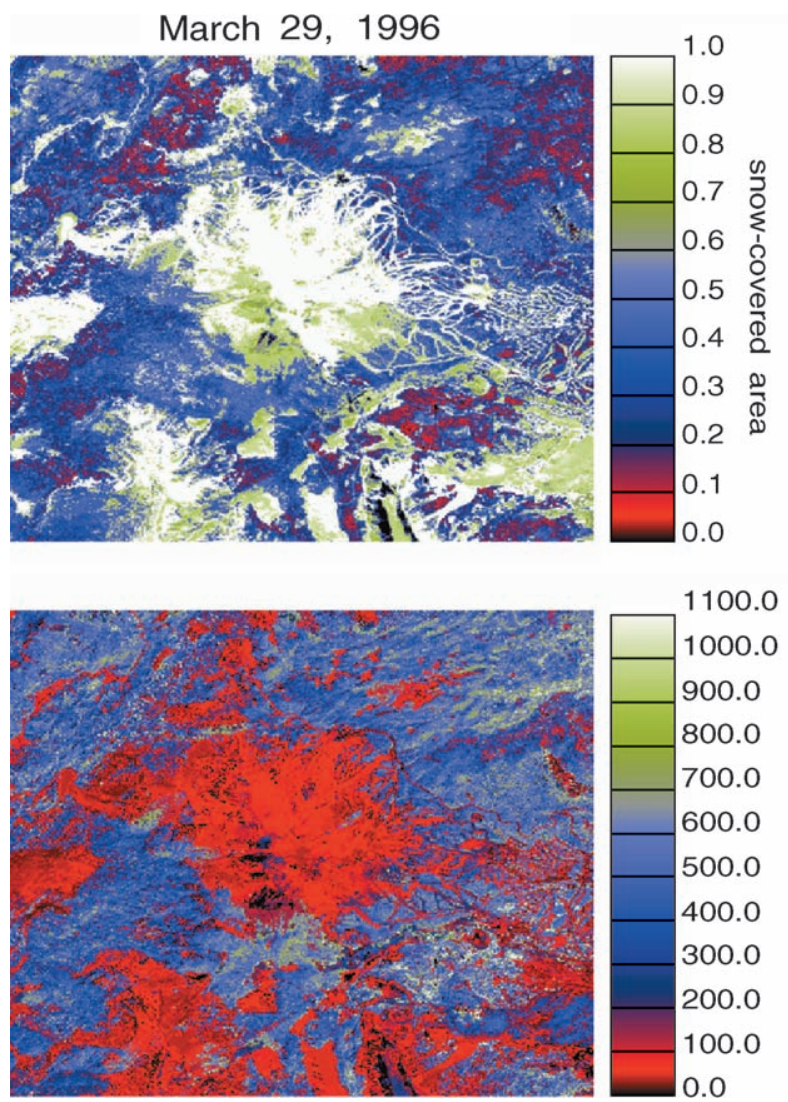

Fig. 9. MEMSCAG snow-covered area and grain size for the AVIRIS acquisition on March 29, 1996.

size for those regions free of vegetation. However, MEMSCAG maps vegetated regions as having much larger grain radii than vegetation-free regions, in a proportional relationship with vegetation density. The errors are consistent in magnitude but opposite in sign with those errors caused by increasing vegetation fraction in the sensitivity study. It is unclear why the errors are opposite in sign to our sensitivity study, but may result from shading of the snow substrate with increasing canopy density, an effect that the sensitivity study did not model. A more complete treatment would use a hybrid geometric optics/radiative transfer model (e.g., Ni, Woodcock, Li, \& Strahler, 1999) to determine the relative spectral fractions of directly illuminated snow, directly illuminated vegetation, and vegetation-shaded snow. While grain-size variability may indeed contribute to the apparent variability that the images show, the combined effects of absorption by liquid water in the vegetation and vegetation shading of the snow cover are more likely to be confounding the spectroscopic analysis.

\subsection{Snow-area validation}

In Fig. 11, we compare the MEMSCAG-derived snow fraction with the photographic derived snow fraction. For all years combined, the root mean squared error in snowcovered area was $4.0 \%$. The respective RMS errors for the
April 29, 1998
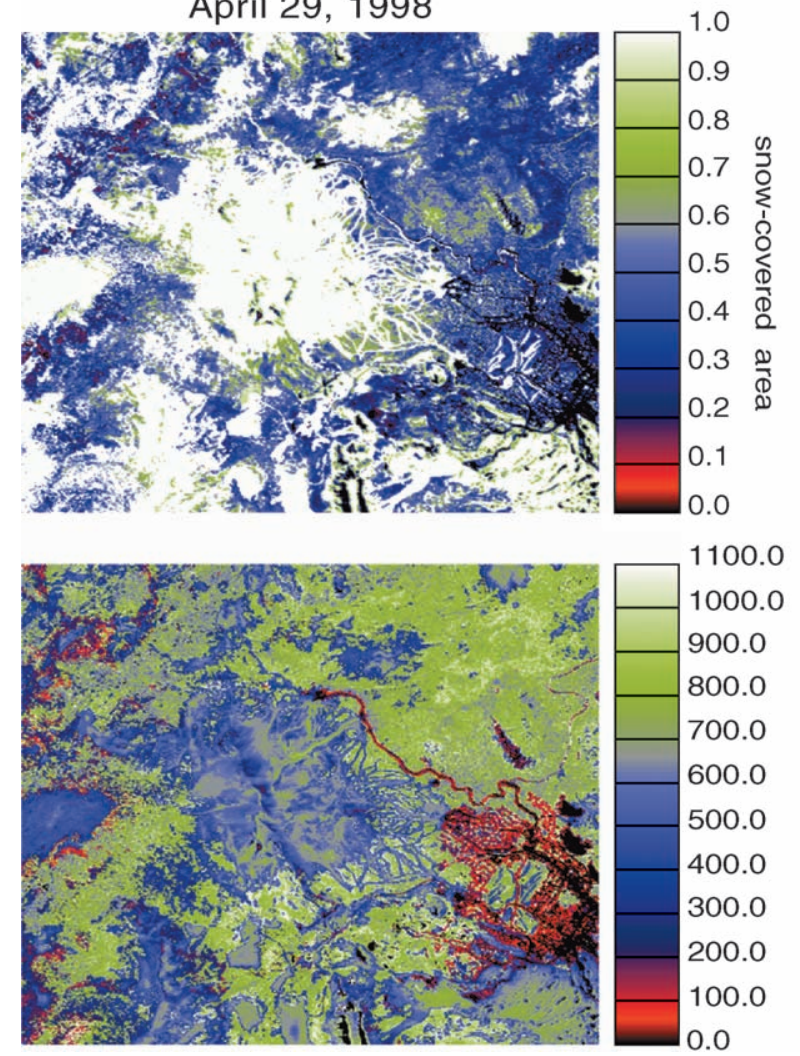

1100.0 1000.0 900.0

(1)

Fig. 10. MEMSCAG snow-covered area and grain size for the AVIRIS acquisition on April 29, 1998.

1994, 1996, and 1998 acquisitions were 3.5\%, 4.5\%, and $4.0 \%$. In a regression analysis of these data, the $95 \%$ confidence intervals for slope and $y$-intercept were [0.94,1.01]

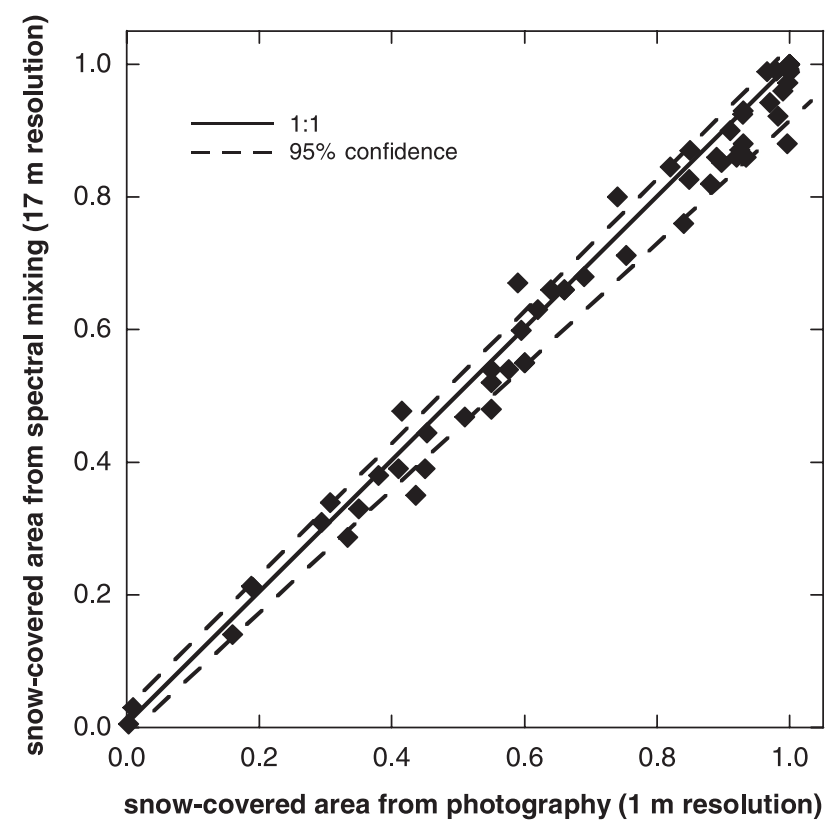

Fig. 11. Validation of snow-covered area for 1994, 1996, and 1998 MEMSCAG retrievals. 
and $[-0.02,0.03]$. Therefore, at a $95 \%$ confidence level, the slope and $y$-intercept were not significantly different from 1.0 to 0.0 and the MEMSCAG snow-area retrieval had comparable accuracy to that of fine-resolution aerial photographs.

\subsection{Grain-size validation}

Given the location uncertainty of snow samples discussed in Section 5.2 and co-registration errors of $\sim 1$ pixel, we validated grain size over $3 \times 3$ search windows about the pixels containing the coordinates of the snow sample locations, and we present results for mean values and closest values within the search windows. In Fig. 12, we compare the mean and closest MEMSCAG-derived snow grain radii with those derived from stereological analysis. The vertical bars in Fig. 12 represent the spans of grain radii in the $3 \times 3$ windows about the apparent points of collection. Because of errors in grain size associated with vegetation density, we have eliminated pixels from each search window if the vegetation fraction $f_{\mathrm{v}}$ exceeds $20 \%$.

For the mean grain size from the $3 \times 3$ window around the apparent pixel of the snow sample, the RMS error for grain size for the combined set of three images was $74 \mu \mathrm{m}$, with
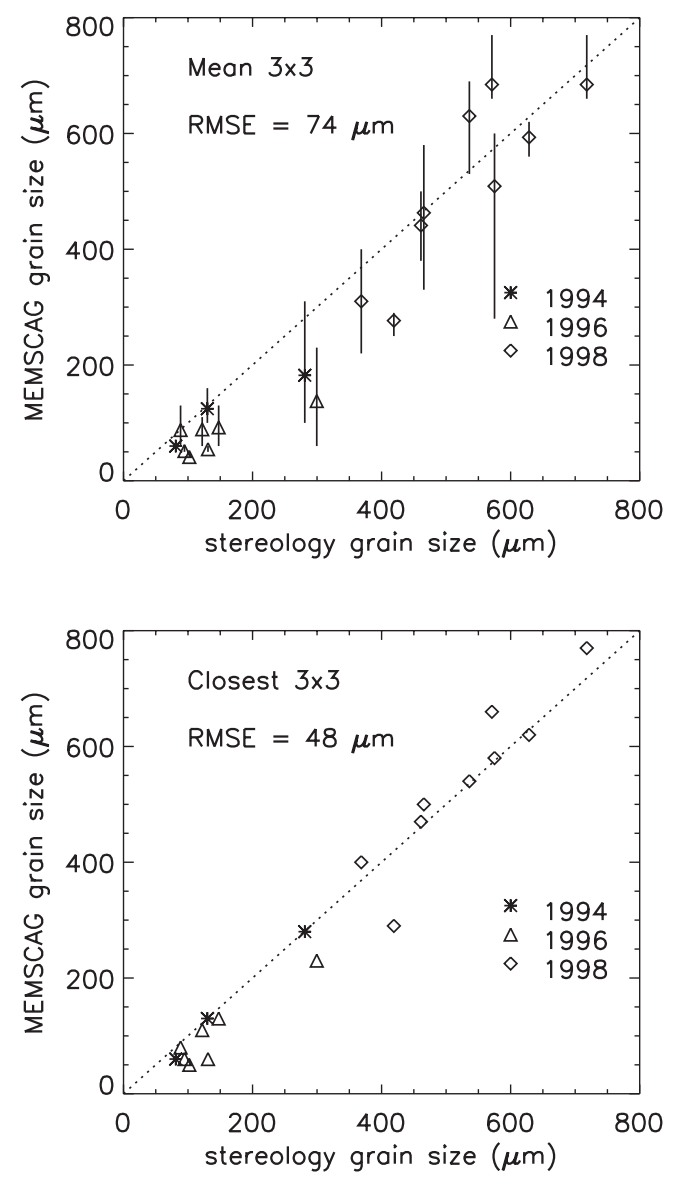

Fig. 12. MEMSCAG grain size validations with mean of $3 \times 3$ window and closest grain size of $3 \times 3$ window; the dashed line represents the 1:1 line.
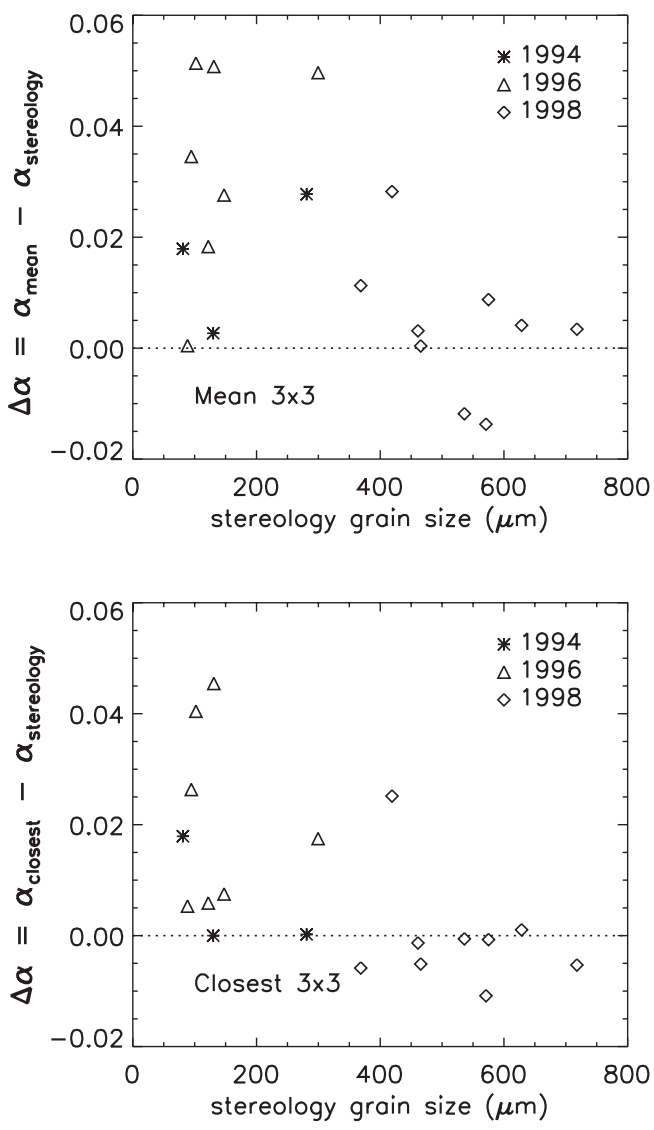

Fig. 13. MEMSCAG albedo errors versus stereology grain size for mean grain sizes in $3 \times 3$ windows and closest grain sizes in $3 \times 3$ window.

respective errors of $58 \mu \mathrm{m}$ (April 5, 1994), $77 \mu \mathrm{m}$ (March 29, 1996), and $76 \mu \mathrm{m}$ (April 29, 1998). The best-case root mean squared error for snow grain size retrieved from the $3 \times 3$ window of AVIRIS data for the combined set of three images is $48 \mu \mathrm{m}$, with respective errors of $12 \mu \mathrm{m}$ (April 5, 1994), 45 $\mu \mathrm{m}$ (March 29, 1996), and $57 \mu \mathrm{m}$ (April 29, 1998). The scale of spatial variability of snow grain size can be quite small and depends on the scale of topographic variability that, in places, may be of the order of a $17-\mathrm{m}$ pixel.

More pertinent is the effect that grain-size errors have on inferred albedo (spectral albedo integrated over wavelength for the atmospheric conditions and solar ephemeris, weighted by the spectral irradiance at the snow surface). Fig. 13 shows the errors in albedo $(\Delta \alpha)$, which decreases from a range of $0.0-0.05$ at small grain sizes to less than

Table 2

Comparison of MEMSCAG-inferred, wavelength-integrated albedo and albedo measured at the Mammoth Mountain Cooperative Snow Study Site

\begin{tabular}{llll}
\hline & $\begin{array}{l}\text { April 5, } \\
1994\end{array}$ & $\begin{array}{l}\text { March 29, } \\
1996\end{array}$ & $\begin{array}{l}\text { April 29, } \\
1998\end{array}$ \\
\hline $\begin{array}{l}\text { Mammoth Mountain } \\
\text { Study Site }\end{array}$ & 0.73 & 0.72 & 0.61 \\
MEMSCAG & 0.77 & 0.79 & 0.67 \\
\hline
\end{tabular}


0.01 for grain sizes greater than $600 \mu \mathrm{m}$. These results suggest that MEMSCAG maps albedo with a decreasing error as the snow grain size increases. The respective root mean squared errors for albedo for the mean and closest grain sizes were 0.025 and 0.018 .

In Table 2, we compare the MEMSCAG albedo and the albedo measured at the Mammoth Mountain Cooperative Snow Study Site (Painter et al., 2000). Errors ranged from $4 \%$ to $7 \%$ overestimates by MEMSCAG across the three acquisitions. The omission of snow impurities from the MEMSCAG model should contribute to the albedo overestimates, particularly on the April 29, 1998 acquisition when the snow surface had a visible dirty layer.

However, sampling problems at the study site should likewise bias measurements to an underestimate of the albedo. The study site's measurement of snow albedo comes from the ratio of level downward and upward looking Eppley Precision Spectral Pyranometer readings. The snow surface underneath the downward looking pyranometer usually accumulates such that it has a slight slope with aspect in the northwest quadrant. Therefore, the measurement of reflected solar radiation will be lower than that from a level surface and in turn, the albedo will be underestimated. An additional sampling problem comes from the placement of the downward looking pyranometer, about $6 \mathrm{~m}$ above the soil surface to allow for snow accumulation. Unless the snow has a depth near $6 \mathrm{~m}$, the pyranometer's field of view includes vegetation and the study site's support frame, both of which will contribute lower radiance than snow. Therefore, even if the snow surface were level, the downward measurement will be too low and the snow albedo will be underestimated.

We calculated the local view angles (from zenith) using the SRTM digital elevation model (DEM) for Mammoth Mountain and the scan angle of AVIRIS $\left(15^{\circ}\right.$ either side of nadir) (Fig. 14). The mean view angle was $13^{\circ}$ with a standard deviation of $11^{\circ}$. View angles greater than $40^{\circ}$

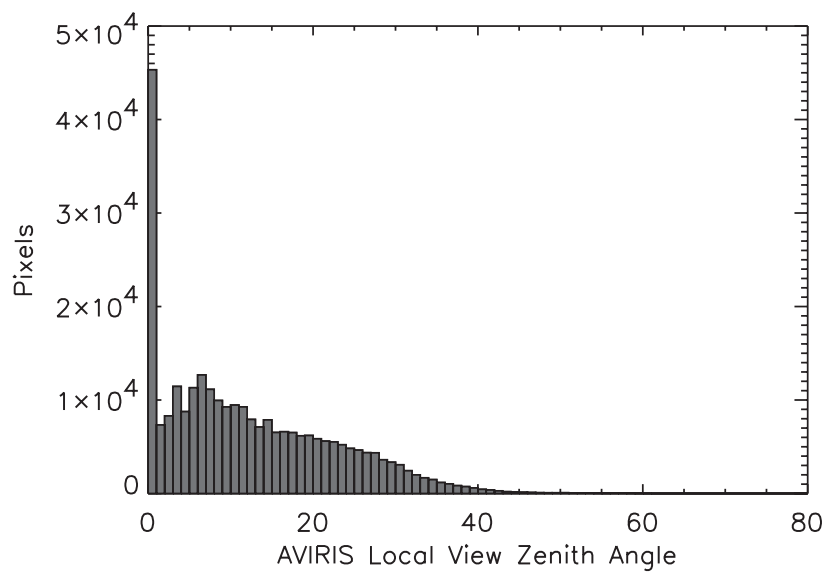

Fig. 14. Histogram of local view zenith angles for AVIRIS calculated from the Shuttle Radar Topography Mission DEM for Mammoth Mountain, California. represent less than $1 \%$ of the imaged domain. MEMSCAG has little sensitivity to the anisotropic reflectance of snow for view angles less than $40^{\circ}$ (Painter, 2002). Therefore, we may apply the model to AVIRIS data under these viewing and illumination conditions and get small errors for snow area and grain size. However, future spaceborne imaging spectrometers will have larger view angles and will image regions under larger solar zenith angles. For those cases, we must expand our work to include ancillary topographic data and a bidirectional reflectance spectral library.

\section{Conclusions}

The multiple endmember snow-covered area and grainsize (MEMSCAG) model couples spectral mixture analysis with a radiative transfer model to map subpixel snowcovered area and the grain size of the snow cover simultaneously, without topographic data. The model infers a value of snow albedo from the grain-size estimate and solar geometry. The snow spectral library for mixture analysis consists of spectra generated with the discrete-ordinates method for snow with sphere radii ranging from 10 to $1100 \mu \mathrm{m}$.

We validated MEMSCAG with three AVIRIS acquisitions that had snow conditions ranging from fresh, finegrain snow to coarse, melting snow. For all acquisitions, MEMSCAG had a 4\% RMSE for snow-covered area, compared to snow area determined with high-resolution photographs. For grain radii ranging from 80 to $750 \mu \mathrm{m}$, MEMSCAG had a RMSE for grain size of $74 \mu \mathrm{m}$ for the mean of $3 \times 3$-pixel AVIRIS windows. For the closest grain size within the $3 \times 3$ windows, the RMSE was $48 \mu \mathrm{m}$. The errors for inferred albedo were 0.025 and 0.018 for the mean and closest grain sizes in the $3 \times 3$ windows.

A sensitivity study shows that MEMSCAG grain-size estimates for a nadir view should have errors less than $10 \%$ for snow area down to $20 \%$ of a pixel when the non-snow constituent is rock and down to between $50 \%$ and $75 \%$ of the pixel, depending on particle size, when the non-snow constituent is vegetation.

While the aerosol optical depth over Mammoth Mountain during these acquisitions was small, other snow-covered regions have more turbid atmospheres. Stroeve, Nolin, and Steffen (1997) found that small amounts of unaccounted-for aerosol may lead to erroneous retrieved reflectance. Further research should explore the sensitivity of MEMSCAG to errors in atmospheric correction.

Because MEMSCAG utilizes the whole AVIRIS spectrum rather than specific absorption features, it is applicable to data from other spectroradiometers that have bands that are sensitive to grain size, such as the EOS Moderate Resolution Spectroradiometer (MODIS). The MODIS band centered at $1.24 \mu \mathrm{m}$ might prove sensitive enough to map subpixel snow area and grain size. However, AVIRIS will likely have less sensitivity to individual band noise. Furthermore, MODIS's 
$0.5-1.0-\mathrm{km}$ footprint increases the likelihood of spatial mixing hurdles such as multiple slopes and aspects, discrete surface grain sizes, or vegetation types within a pixel. We will address these issues in future research.

\section{Acknowledgements}

This research was performed at the Institute for Computational Earth System Science at the University of California, Santa Barbara under funding from the NASA grant NAG54514 and Los Alamos National Laboratory grant STB/ UC:95-50. We thank Thomas Albright, Hayden Dozier, Robert Harrington, Darla Heil, Tammy Johnson, Rick Kattelman, and Walter Rosenthal for their help with field measurements during AVIRIS campaigns. We also appreciate the helpful comments of three anonymous referees.

\section{References}

Adams, J. B., Smith, M. O., \& Gillespie, A. R. (1993). Imaging spectroscopy: Interpretation based on spectral mixture analysis. In C. M. Pieters, \& P. A. J. Englert (Eds.), Remote geochemical analysis: elemental and mineralogical composition (pp. 145-166). New York: Cambridge Univ. Press.

Berk, A., Bernstein, L. S., Anderson, G. P., Acharya, P. K., Robertson, D. C., Chetwynd, J. H., \& Adler-Golden, S. M. (1998). MODTRAN cloud and multiple scattering upgrades with application to AVIRIS. Remote Sensing of Environment, 65(3), 367-375.

Bourdelles, B., \& Fily, M. (1993). Snow grain-size determination from Landsat imagery over Terre Adélie, Antarctica. Annals of Glaciology, $17,86-92$.

Cline, D. W., Bales, R. C., \& Dozier, J. (1998). Estimating the spatial distribution of snow in mountain basins using remote sensing and energy balance modeling. Water Resources Research, 34(5), 1275-1285.

Colee, M. T., Painter, T. H., Rosenthal, W., \& Dozier, J. (2000). A spatially distributed physical snowmelt model in an alpine catchment. Proceedings of the Western Snow Conference, 68, 99-102.

Davis, R. E., Dozier, J., \& Perla, R. (1987). Measurement of snow grain properties. In W. J. Orville-Thomas, \& H. G. Jones (Eds.), Seasonal snowcover: physics, chemistry, hydrology. NATO ASI Series C: Mathematical and Physical Sciences, vol. 211 (pp. 53-74). Dordrecht: D. Reidel.

Dozier, J. (1989). Spectral signature of alpine snow cover from the Landsat Thematic Mapper. Remote Sensing of Environment, 28(1), 9-22.

Dozier, J., \& Marks, D. (1987). Snow mapping and classification from Landsat Thematic Mapper data. Annals of Glaciology, 9, 97-103.

Dozier, J., Schneider, S. R., \& McGinnis Jr., D. F. (1981). Effect of grain size and snowpack water equivalence on visible and near-infrared satellite observations of snow. Water Resources Research, 17(4), 1213-1221.

Fily, M., Bourdelles, B., Dedieu, J. P., \& Sergent, C. (1997). Comparison of in situ and Landsat Thematic Mapper derived snow grain characteristics in the Alps. Remote Sensing of Environment, 59(3), 452-460.

Gillespie, A. R., Smith, M. O., Adams, J. B., Willis, S. C., Fischer III, A. F., \& Sabol, D. E. (1990). Interpretation of residual images: spectral mixture analysis of AVIRIS images, Owens Valley, California. Second Airborne Visible/Infrared Imaging Spectrometer (AVIRIS) Workshop, vol. 90-54 (pp. 243-270). Pasadena, CA: Jet Propulsion Laboratory.

Golub, G. H., \& Van Loan, C. F. (1996). Matrix Computations. (3rd ed.). Baltimore: Johns Hopkins Univ. Press (694 pp.).
Green, R. O. (2001). Atmospheric water vapor sensitivity and compensation requirement for Earth-looking imaging spectrometers in the solarreflected spectrum. Journal of Geophysical Research, 106(D15), $17443-17452$.

Green, R. O., Conel, J. E., \& Roberts, D. A. (1993). Estimation of aerosol optical depth, pressure elevation, water vapor, and calculation of apparent surface reflectance from radiance measured by the airborne visible/ infrared imaging spectrometer (AVIRIS) using MODTRAN2. In G. Vane (Ed.), Imaging spectrometry of the terrestrial environment, vol. 1937 (pp. 2-11). Proceedings of SPIE.

Green, R. O., Dozier, J., Roberts, D. A., \& Painter, T. H. (2002). Spectral snow reflectance models for grain size and liquid water fraction in melting snow for the solar reflected spectrum. Annals of Glaciology, $34,71-73$.

Green, R. O., Eastwood, M. L., Sarture, C. M., Chrien, T. G., Aronsson, M., Chippendale, B. J., Faust, J. A., Pavri, B. E., Chovit, C. J., Solis, M., Olah, M. R., \& Williams, O. (1998). Imaging spectroscopy and the Airborne Visible/Infrared Imaging Spectrometer. Remote Sensing of Environment, 65(3), 227-248.

Hall, D. K., Riggs, G. A., \& Salomonson, V. V. (1995). Development of methods for mapping global snow cover using Moderate Resolution Imaging Spectroradiometer data. Remote Sensing of Environment, 54(2), $127-140$.

Kirnbauer, R., Blöschl, G., \& Gutknecht, D. (1994). Entering the era of distributed snow models. Nordic Hydrology, 25(1-2), 1-24.

Leroux, C., Deuze, J. L., Goloub, P., Sergent, C., \& Fily, M. (1998). Ground measurements of the polarized bidirectional reflectance of snow in the near-infrared spectral domain: comparisons with model results. Journal of Geophysical Research, 103(D16), 19721-19731.

Luce, C. H., Tarboton, D. G., \& Cooley, K. R. (1998). The influence of the spatial distribution of snow on basin-averaged snowmelt. Hydrological Processes, 12(10-11), 1671-1683.

Luce, C. H., Tarboton, D. G., \& Cooley, K. R. (1999). Sub-grid parameterization of snow distribution for an energy and mass balance snow cover model. Hydrological Processes, 13(12-13), 1921-1933.

Mätzler, C. (1997). Autocorrelation functions of granular media with free arrangement of spheres, spherical shells or ellipsoids. Journal of Applied Physics, 81(3), 1509-1517.

Mertes, L. A. K., Smith, M. O., \& Adams, J. B. (1993). Estimating suspended sediment concentrations in surface waters of the Amazon River wetlands from Landsat images. Remote Sensing of Environment, 43(3), $281-301$.

Mie, G. (1908). Beiträge zur Optik trüber Medien, Speziell Kolloidaler Metallösungen. Annales de Physique, 25, 377-445.

Ni, W., Woodcock, C. E., Li, X., \& Strahler, A. H. (1999). An analytical hybrid GORT model for bidirectional reflectance over discontinuous plant canopies. IEEE Transactions on Geoscience and Remote Sensing, 37(2), 987-999.

Nolin, A. W., \& Dozier, J. (1993). Estimating snow grain size using AVIRIS data. Remote Sensing of Environment, 44(2-3), 231-238.

Nolin, A. W., \& Dozier, J. (2000). A hyperspectral method for remotely sensing the grain size of snow. Remote Sensing of Environment, 74(2), 207-216.

Nolin, A. W., Dozier, J., \& Mertes, L. A. K. (1993). Mapping alpine snow using a spectral mixture modeling technique. Annals of Glaciology, 17, $121-124$.

Nussenzveig, H. M., \& Wiscombe, W. J. (1980). Efficiency factors in Mie scattering. Physical Review Letters, 45(18), 1490-1494.

Okin, G. S., Roberts, D. A., Murray, B., \& Okin, W. J. (2001). Practical limits on hyperspectral vegetation discrimination in arid and semiarid environments. Remote Sensing of Environment, 77(2), 212-225.

Painter, T. H., 2002. The hyperspectral bidirectional reflectance of snow: modeling, measurement, and instrumentation, $\mathrm{PhD}$ Thesis, Department of Geography, University of California, Santa Barbara (289 pp.).

Painter, T. H., Donahue, D., Dozier, J., Li, W., Kattelmann, R., Dawson, D., Davis, R. E., Fiori, J., Harrington, B., \& Pugner, P. (2000). The Mammoth Mountain cooperative snow study site: data acquisition, manage- 
ment, and dissemination. Proceedings International Snow Science Workshop, ISSW, 447-451.

Painter, T. H., Duval, B., Thomas, W. H., Mendez, M., Heintzelman, S., \& Dozier, J. (2001). Detection and quantification of snow algae with an airborne imaging spectrometer. Applied and Environmental Microbiology, 67(11), 5267-5272.

Painter, T. H., Roberts, D. A., Green, R. O., \& Dozier, J. (1998). The effect of grain size on spectral mixture analysis of snow-covered area from AVIRIS data. Remote Sensing of Environment, 65(3), 320-332.

Rango, A., \& Itten, K. (1976). Satellite potentials in snowcover monitoring and runoff prediction. Nordic Hydrology, 7, 209-230.

Ray, T. W., \& Murray, B. C. (1996). Nonlinear spectral mixing in desert vegetation. Remote Sensing of Environment, 55(1), 59-64.

Ricchiazzi, P., Yang, S. R., Gautier, C., \& Sowle, D. (1998). SBDART: A research and teaching software tool for plane-parallel radiative transfer in the Earth's atmosphere. Bulletin of the American Meteorological Society, 79(10), 2101-2114.

Roberts, D. A., Gardner, M., Church, R., Ustin, S., Scheer, G., \& Green, R. O. (1998). Mapping chaparral in the Santa Monica Mountains using multiple endmember spectral mixture models. Remote Sensing of Environment, 65(3), 267-279.

Roberts, D. A., Smith, M. O., \& Adams, J. B. (1993). Green vegetation, nonphotosynthetic vegetation, and soils in AVIRIS data. Remote Sensing of Environment, 44(2-3), 255-269.

Rosenthal, W., \& Dozier, J. (1996). Automated mapping of montane snow cover at subpixel resolution from the Landsat Thematic Mapper. Water Resources Research, 32(1), 115-130.

Sabol Jr., D. E., Adams, J. B., \& Smith, M. O. (1992). Quantitative subpixel spectral detection of targets in multispectral images. Journal of Geophysical Research, 97(E2), 2659-2672.

Shi, J., \& Dozier, J. (2000a). Estimation of snow water equivalence using
SIR-C/X-SAR: Part I. inferring snow density and subsurface properties. IEEE Transactions on Geoscience and Remote Sensing, 38(6), $2465-2474$.

Shi, J., \& Dozier, J. (2000b). Estimation of snow water equivalence using SIR-C/X-SAR: Part II. Inferring snow depth and grain size. IEEE Transactions on Geoscience and Remote Sensing, 38(6), $2475-2488$.

Stamnes, K., Tsay, S. -C., Wiscombe, W. J., \& Jayaweera, K. (1988). Numerically stable algorithm for discrete-ordinate-method radiative transfer in multiple scattering and emitting layered media. Applied $O p$ tics, 27(12), 2502-2509.

Stroeve, J., Nolin, A., \& Steffen, K. (1997). Comparison of AVHRR-derived and in situ surface albedo over the Greenland ice sheet. Remote Sensing of Environment, 62(3), 262-276.

van Zyl, J. J. (2001). The Shuttle Radar Topography Mission (SRTM): A breakthrough in remote sensing of topography. Acta Astronomica, $48(5-12), 559-565$.

Warren, S. G. (1982). Optical properties of snow. Reviews of Geophysics and Space Physics, 20(1), 67-89.

Warren, S. G., Brandt, R. E., \& Hinton, P. O. (1998). Effect of surface roughness on bidirectional reflectance of Antarctic snow. Journal of Geophysical Research, 103(E11), 25789-25807.

Warren, S. G., \& Wiscombe, W. J. (1980). A model for the spectral albedo of snow, II, snow containing atmospheric aerosols. Journal of Atmospheric Science, 37(12), 2734-2745.

Wiscombe, W. J. (1980). Improved Mie scattering algorithms. Applied Optics, 19(9), 1505-1509.

Wiscombe, W. J., \& Warren, S. G. (1980). A model for the spectral albedo of snow, I, pure snow. Journal of the Atmospheric Science, 37(12), $2712-2733$. 